\title{
Long memory forecasting of yield spreads using a fractionally integrated ARMA model and its application in Islamic capital market
}

\author{
Issam Bousalam* and \\ Moustapha Hamzaoui
}

Department of Economics,

Abdelmalek Essaädi University of Tangier, Morocco

Email: boussalam.issam@gmail.com

Email: moustaphahamzaoui@gmail.com

*Corresponding author

\begin{abstract}
In this paper, we used a modified rescaled range analysis (MRS) to investigate the presence of long memory in three series of absolute yield spreads (AYS) of the Dow Jones Sukuk Indexes from March 1, 2011 to March 1, 2016. The estimated Hurst exponents for the three series are significant and smaller than one providing strong evidence that long range dependence exists in Sukuk's AYS and these can become stationary with fractional differencing. Based on these results, we fitted three ARFIMA models to Sukuk's AYS and found that they have better explanatory power compared to the first-order ARIMA models. Furthermore, our 260 steps-ahead dynamic forecasting results show that the ARFIMA models are better for predicting future yield spreads. Such findings suggest to account for long memory in investing decisions and projecting future yields and spreads. Our results should be useful to Sukuk market participants whose success depends on the ability to forecast Sukuk's yield spreads movements, and anticipate the prospective default risk.
\end{abstract}

Keywords: long memory; ARFIMA model; Sukuk; yield spreads analysis; YSA; Islamic indexes.

Reference to this paper should be made as follows: Bousalam, I. and Hamzaoui, M. (2017) 'Long memory forecasting of yield spreads using a fractionally integrated ARMA model and its application in Islamic capital market', Int. J. Bonds and Derivatives, Vol. 3, No. 1, pp.71-92.

Biographical notes: Issam Bousalam is a $\mathrm{PhD}$ candidate at Abdelmalek Essaadi University of Tangier, Morocco. He is a member of the research team Economie, Finance et Développement.

Moustapha Hamzaoui is a $\mathrm{PhD}$ Professor of Economics and Finance at Abdelmalek Essaädi University of Tangier, Morocco. He is the head of research team Economie, Finance et Développement.

\section{Introduction}

One of the most helpful tools for investors to understand the market's tendency and the direction the economy is going to take is yield spreads analysis (YSA). By definition, a 
yield spread is the difference between the quoted rates of return on two different investments, and the yield spread of financial instrument A over B is calculated by subtracting the annualised percentage return on investment (ROI) of financial instrument $\mathrm{B}$ from that of instrument $\mathrm{A}$. The magnitude of this gap indicates the risk premium for investing in one investment product over another. In fact, when spreads widen between bond categories with different credit ratings, it implies that the market is factoring more risk of default on lower grade bonds. The anticipation of greater risk of default implies a slowing economy. On the other hand, a narrowing of spreads implies that the market is factoring in less risk. This might be due to higher expectation of economic growth (Simkovic and Kaminetzky, 2011).

In this paper, we investigate the presence of long memory in the yield spreads of some indexes within the Dow Jones Sukuk Index (DJSI) family. A significant evidence of the presence of a long memory in the processes of the analysed yield spreads indicates that long-range dependence could serve as a forecasting tool in Islamic capital market to anticipate prospective default risk.

Concretely, we fit an autoregressive (AR) fractionally integrated moving average (ARFIMA) model to three series of yield spreads. These are:

1 yield spreads of the DJSI AA rated over the DJSI AAA rated

2 yield spreads of the DJSI A rated over the DJSI AAA rated

3 yield spreads of DJSI BBB rated over the DJSI AAA rated.

The triple A rated DJSI is constantly the benchmark. Next, we compare the forecasting outcome of $\operatorname{ARFIMA}(p, d, q)$ model to that of other competing models (namely, $\operatorname{ARIMA}(p, d, q)$ and $\operatorname{ARMA}(p, q))$ for the three series.

\subsection{Background of Sukuk and their indexes}

Sukuk is the Arabic name for financial certificates commonly referred to as Sharia (Islamic law) compliant bonds. Sukuk are defined by the Accounting and Auditing Organization for Islamic Financial Institutions (AAOIFI) as "securities of equal denomination representing individual ownership interests in a portfolio of eligible existing or future assets."

The DJSI family is designed to measure the performance of global Islamic fixed-income securities (Sukuk). The indexes include US dollar-denominated investment-grade Sukuk issued in the global market that have been screened for Shariah compliance according to the index methodology. The indexes were created as a benchmark for investors seeking exposure to Shariah-compliant fixed-income investments. There exist 11 Dow Jones Sukuk indexes (DJSI) with different maturities and ratings, and these are calculated using market capitalisation methodology and are updated monthly. ${ }^{2}$

It is noteworthy that Sukuk are the most active Islamic debt market financial instruments to date. Therefore, empirical study on Sukuk market behaviour in terms of the long range dependence will help both investors and issuers understand more the structure and price risk exposures of these instruments. Defining the best fitting ARFIMA model for yield spreads of different rated Sukuk is of paramount importance. We recall that this paper uses one main index (DJSI AAA rated) as the benchmark and three other indexes (DJSI AA rated, DJSI A rated and DJSI BBB rated) to calculate the Sukuk yield spreads. 


\subsection{ARFIMA framework}

Financial literature often notes that financial markets are not Gaussian in nature and tend to have sharper peaks and fat tails. Such evidence hinders the use of number of traditional methods based on Gaussian normality in providing accurate forecasts (Peters, 1994).

Another key point explained by Peters (1994) is the fact that most financial markets have long memory feature. This means that events happening today on the market influence the future. In other words, the current data is correlated to past data with different varying degrees.

One of the downsides of systems that work with short-memory is their inability to adequately explain long memory component of the markets. Traditional models describing short-term memory, such as $\operatorname{AR}(p), \operatorname{MA}(q), \operatorname{ARMA}(p, q)$, and $\operatorname{ARIMA}(p, d$, $q$ ) use the last $i$ values for making the forecast in univariate analysis, i.e., for these statistical methods, the lagged $i$ observations are considered when predicting values of time $i+1$. In order to overcome this issue, a set of models was developed and the most famous one is the so-called $\operatorname{ARFIMA}(p, d, q)$ introduced by Granger and Joyeux (1980).

Baillie (1996) provided an excellent survey and review of the major econometric works on long memory processes, fractional integration, and their applications in economics and finance. More recent important contributions in this area, both from a theoretical and an empirical perspective include the papers below. In a theoretical framework, a list of few important contributions covers (Granger, 1980; Hosking, 1981; Lo, 1989; Sowell, 1992a, 1992b; Ding et al., 1993; Cheung and Diebold, 1994; Robinson, 1995b, 1995a; Engle and Smith, 1999; Diebold and Inoue, 2001; Breitung and Hassler, 2002; Dittmann and Granger, 2002). From an empirical perspective, long-memory models has also been impressively treated by Diebold and Rudebusch $(1989,1991 \mathrm{~b}$, 1991a), Hassler and Wolters (1995), Bos et al. (2002), Van Dijk et al. (2002), Grech and Mazur (2004), Carbone et al. (2004), Di Matteo et al. (2005), Hyung et al. (2006), Choi and Zivot (2007), Di Matteo (2007), Matos et al. (2008), Alvarez-Ramirez et al. (2008), and Czarnecki et al. (2008), to name but a few. ${ }^{3}$ This non-exhaustive list of papers on the subject of long-memory models is not impressive given the fact that long memory forecasting in economics has been considered as one of the many important areas of research as it was stated by the Royal Swedish Academy of Sciences on the announcement of the Nobel Prize winners in Economics in 2003, Clive W.J. Granger and Robert F. Engle. ${ }^{4}$

An ARFIMA model is a special case of ARIMA models and exhibits long memory when its fractional integration parameter $d$ is greater than zero. Stationary long-memory models $(0<d<0.5)$, also fractionally integrated ARMA (ARFIMA) models, have been considered by researchers in many fields and much studies were mainly motivated by the fact that the autocorrelation function (ACF) of many empirical times series declines at a slower rate than for an ARIMA model with finite orders and integer d. Also, the comparison of forecasting potential of fitted ARFIMA models against other time series model, has been a topic of various papers and a special issue.

Indeed, Ray (1993a, 1993b) compared the seasonal ARFIMA models and standard (non-fractional) seasonal ARIMA models and found that higher order AR models are capable of forecasting the longer term well when compared with ARFIMA models. Following this later, Smith and Yadav (1994) investigated the cost of assuming a unit difference when a series is only fractionally integrated with $d \neq 1$. 
Over-differencing a series produces significant loss in forecasting performance one-step-ahead, with only a limited loss thereafter. In contrary, under-differencing a series is more costly with larger potential losses from fitting a mis-specified AR model at all forecast horizons. By using a rule which is similar to the test of (Öller, 1985), Andersson (2000) explored this issue and showed that misspecification strongly affects the estimated memory of the ARFIMA model. Man (2003) argued that a suitably adapted $\operatorname{ARMA}(2,2)$ model can produce short-term forecasts that are competitive with estimated ARFIMA models. Man (2003) developed the multi-step-ahead forecasts of long-memory models which were compared by Bhansali and Kokoszka (2002).

Researchers have developed many extensions of the ARFIMA models and compared their relative forecasting performance. For example, Franses and Ooms (1997) introduced the so-called periodic $\operatorname{ARFIMA}(0, d, 0)$ model where $d$ can vary with the seasonality parameter. Ravishanker and Ray (2002) explored the estimation and forecasting of multivariate ARFIMA models. Baillie and Chung (2002) discussed the use of linear trend-stationary ARFIMA models, while Beran et al. (2002) extended this model to allow for nonlinear trends. Souza and Smith (2002) used different sampling rates, such as monthly versus quarterly data in order to investigate their effect on estimates of the long-memory parameter $d$. In a similar concern, Souza and Smith (2004) looked at the effects of temporal aggregation on estimates and forecasts of ARFIMA processes. In the context of statistical quality control, Ramjee et al. (2002) introduced a hyperbolically weighted moving average forecast-based control chart, designed specifically for non-stationary ARFIMA models.

The remaining of this paper is organised as follows, Section 2 presents the ARFIMA model with its establishing procedure and describes the data, Section 3 presents the estimates for ARIMA vs. ARFIMA models and the forecasting results, and Section 4 serves to conclude.

\section{Materials and methods}

\subsection{The procedure of establishing an ARFIMA model}

The process of fitting an ARFIMA model to financial data is of three steps. The first one consists in testing for the presence of long-term memory in the time series, and determining the fractional differencing parameter $d$. Second, the fractional parameter $d$ is imposed on the series to obtain an ARMA process. Thirdly, determining the other two parameters of $\operatorname{ARFIMA}(p, d, q)$ model, namely $p$ and $q$.

\subsubsection{Fractional differencing and long memory}

Financial time series are mostly non-stationary, and the transformation of a non-stationary time series into a stationary one has long been an important issue in the field of time series analysis. Since modelling time series requires prior stationarity, a common standard practice that has been used by time series analysts was to consider differencing their time series to achieve stationarity. However, econometricians were somehow reluctant to accept this, believing that they may lose something of importance.

Let's consider an $\operatorname{ARFIMA}(0, d, 0)$ as an example. This process is expressed by $(1-L)^{d} x_{i}=\epsilon_{t}$ and is called the fractional white noise. For $d=0$, the process is a white 
noise and its ACF decreases to zero very quickly. But, when $d=1, x_{i}$ is a random walk whose ACF value is 1 . This random walk is transformed to a white noise after a first-order differencing, and when $d$ is non-integer, the $i^{\text {th }}$ element of the fractional differenced time series is actually the weighted sum of elements of $x_{i}, x_{i-1}, \ldots, x_{0}$ the original time series. The $i^{\text {th }}$ element of the fractional differenced time series is not only determined by $x_{i}$ and $x_{i-1}$, but also influenced by all historical data ahead of $x_{i}$, this is just the characteristic of long-term memory.

\subsubsection{Long memory analysis and determination of integration parameter d}

Scholars have been using various methods when testing for long memory, and the most popular ones are: rescaled range analysis $(\mathrm{R} / \mathrm{S})$, modified rescaled range analysis (MRS), and detrended fluctuation analysis (DFA).

\subsubsection{Rescaled range analysis}

The rescaled range analysis (R/S) was first proposed by Hurst (1951) while working as a water engineer in Egypt, and its purpose is to provide an assessment of how the apparent variability of a series changes with the length of the time-period being considered. The $(\mathrm{R} / \mathrm{S})$ analysis was later applied to financial time series by Mandelbrot and Van Ness (1968) and Mandelbrot (1971).

The basic idea behind (R/S) analysis is that a range, which is taken as a measure of dispersion of the series, follows a scaling law. If a process is random, the measure of dispersion scales according to the square-root law so that a power in the scaling law is equal to 0.5. Such value is connected to Hurst exponent of 0.5 (Weron, 2002).

The procedure of the (R/S) analysis, as explained by Weron (2002), consists in taking returns of the time series of length $T$ and dividing them into $N$ adjacent sub-periods of length $v$ while $N v=T$. Sub-periods are labelled as $I_{n}$ with $n=1,2, \ldots, N$. Also, each element in $I_{n}$ is labelled $r_{k, n}$ with $k=1,2, \ldots, v$. For each sub-period, an average value is calculated and new series of accumulated deviations from the arithmetic mean values are constructed (the profile).

The procedure follows in calculation of the range, which is defined as a difference between a maximum and a minimum value of the profile $X_{k, n}$, and a standard deviation of the original returns series for each sub-period $I_{n}$. Each range $R_{I_{n}}$ is standardised by the corresponding standard deviation $S_{I_{n}}$ and forms a rescaled range as:

$$
(R / S)_{I_{n}}=\frac{R_{I_{n}}}{S_{I_{n}}}=\frac{\left[\max _{0<k<n} \sum_{i=1}^{k}\left(X_{k, n}-\bar{X}_{n}\right)-\min _{0<k<n} \sum_{i=1}^{k}\left(X_{k, n}-\bar{X}_{n}\right)\right]}{S_{I_{n}}} .
$$

The process is repeated for each sub-period of length $v$. We get average rescaled ranges $(\mathrm{R} / \mathrm{S})_{v}$ for each sub-interval of length $v$.

The length $v$ is increased and the whole process is repeated. We use the procedure used in recent papers so that we use the length $v$ equal to the power of a set integer value. Thus, we set a basis $b$, a minimum power $p$ min and a maximum power $p$ max so that we get $v=b^{p \text { min }}, b^{p \min +1}, \ldots, b^{p \max }$ where $b^{p \max } \leq T$. 
Rescaled range then scales as:

$$
(R / S)_{v} \sim c v^{H}
$$

where $c$ is a finite constant independent of $v$ (Di Matteo, 2007). A linear relationship in double-logarithmic scale indicates a power scaling (Weron, 2002). To uncover the scaling law, we use an ordinary least squares (OLS) regression on logarithms of each side of (2). We suggest using logarithm with basis equal to $b$. Thus, we get:

$$
\log _{b}(R / S)_{v} \sim \log _{b} c+H \log _{b} v
$$

where $H$ is Hurst exponent.

Through Monte Carlo simulation, Hurst noted that if the underlying process is a random draw from a stable distribution, then $H=0.5$. If $H$ is greater than 0.5 , there is evidence of persistent dependence (large values followed by large values and small values followed by small values) and if $H$ is less than 0.5 , an ergodic or mean reverting process is indicated. The infinite memory result implies that $H$ will stabilise asymptotic to some value other than 0.5 and will maintain that value no matter how large the sample size. If $0<H<1$ then we can conclude that the underlying time series has long memory.

\subsubsection{Modified rescaled range analysis}

The problem with estimating the Hurst exponent with regression analysis is that the regression coefficients may be biased as a result of autocorrelation. Furthermore, the traditional $(\mathrm{R} / \mathrm{S})$ value is not acceptable since tests of the statistical significance do not exist (Lo, 1991). Therefore, Lo (1991) developed a modified (R/S) statistic where $S_{I_{n}}$ is adjusted for short term dependence. The only difference between $(\mathrm{R} / \mathrm{S})$ and $(\mathrm{R} / \mathrm{S})$ ' values is at denominator of (1) which is as follows.

$$
(R / S)_{I_{n}}^{\prime}=\frac{\left[\max _{0<k<n} \sum_{i=1}^{k}\left(X_{k, n}-\bar{X}_{n}\right)-\min _{0<k<n} \sum_{i=1}^{k}\left(X_{k, n}-\bar{X}_{n}\right)\right]}{\sigma_{I_{n}}(q)},
$$

where

$$
\begin{aligned}
& \sigma_{I_{n}}(q)=\left(S_{I_{n}}+\frac{2}{n} \sum_{j=1}^{q} \omega_{j}(q)\left[\sum_{i=j+1}^{n}\left(X_{i}-\bar{X}_{n}\right)\left(X_{i-j}-\bar{X}_{n}\right)\right]\right)^{\frac{1}{2}}, \\
& \omega_{j}(q)=1-\frac{j}{q+1}, q<n .
\end{aligned}
$$

The process of calculations of $(R / S)_{I_{n}}^{\prime}$ is the same as $(R / S)_{I_{n}}$ except that the denominator of $(R / S)_{I_{n}}^{\prime}$ is the root of the sample variance $S_{I_{n}}$ augmented with weighted auto covariance up to a lag determined $q$. For $q=0$, this is the same as the $(\mathrm{R} / \mathrm{S})$ statistic. This auto covariance part of denominator is non-zero for series exhibiting short-term memory and this makes the statistic robust to heteroscedasticity. 


\subsubsection{Detrended fluctuation analysis}

Peng et al. (1994) were the first to propose the DFA while examining series of DNA nucleotides. Compared to the $(\mathrm{R} / \mathrm{S})$ analysis examined above, DFA uses different measure of dispersion-squared fluctuations around trend of the signal. As DFA is based on detrending of the sub-periods, it can be used for non-stationary time series contrary to $\mathrm{R} / \mathrm{S}$.

The advantages of DFA over above techniques are that it permits the detection of long range correlation embedded in seemingly non-stationary time series, and also avoid the spurious detection of apparent long-range correlation that are an artefact of non-stationary.

The implementation of the DFA requires the time series to be integrated first so that:

$$
x(k)=\sum_{t=1}^{k}\left(x_{t}-\bar{x}\right)
$$

where $x_{t}$ is the $t^{\text {th }}$ observation and $\bar{x}$ the average value of the series. Next, the vertical characteristic scale of the integrated time series is measured. To do so, the integrated time series is divided into $m$ non-overlapping time intervals of length $n$. In each time interval a line is fitted via OLS, which is called the local trend. The $x$ coordinate of the straight line $x$ segments is denoted by $\hat{x}(k)$. Then, the integrated time series $x(k)$ is detrended by subtracting the local trend $\hat{x}(k)$ in each time interval.

$$
x=x(k)-\hat{x}(k)
$$

For a given interval size $n$, the characteristic size of fluctuation for this integrated and detrended time series is calculated by:

$$
F(n)=\sqrt{\frac{1}{N} \sum_{i=1}^{N}\left(x_{i}\right)^{2}}
$$

We repeat the above computation over all time scales to provide a relationship between $F(n)$ and $n$. A power law relation between $F(n)$ and $n$ indicates the presence of scaling that is, $F(n) \approx n^{a}$. The parameter $a$, called the scaling exponent or correlation exponent, represents the correlation properties of time series and is the same Hurst exponent. If $a>0.5$, there are positive correlations in time series.

\subsection{ARIMA and ARFIMA models}

Once the non-stationary series are transformed to a stationary series by differencing, these could be next analysed and modelled like any other stationary time series. Yet, after modelling the differenced time series, the output series is transformed back to the original raw data by reversing the order of differencing. An ARIMA model predicts a value in a response time series as a linear combination of its own past values, past errors, and current and past values of other time series. The order of an ARIMA model is usually denoted by the notation $\operatorname{ARIMA}(p, d, q)$, where $p$ is the order of the AR component, $d$ the order of the differencing, and $q$ the order of the moving-average (MA) process. Mathematically, the ARIMA model is written as: 


$$
\Phi(L)(1-L)^{d} x_{t}=\Theta(L) \epsilon_{t}
$$

where

$L \quad$ the lag operator or backshift operator (i.e., $L x_{t}=x_{t-1}$ ), for all $t>1$

$\Phi(L)$ the AR operator, represented as a polynomial in the backshift operator such that $\Phi(L)=1-\varphi_{1} L^{1}-\varphi_{2} L^{2}-\ldots-\varphi_{p} L^{p}$

$\Theta(L)$ the MA operator, represented as a polynomial in the backshift operator where $\Theta(L)$ $=1-\theta_{1} L^{1}-\theta_{2} L^{2}-\ldots-\theta_{p} L^{p}$

$\epsilon_{t} \quad$ a white noise with zero mean and finite variance $\sigma_{\epsilon}^{2}$.

As for the ARFIMA process, two case scenarios are presented, the stationary and invertible ARFIMA, and the non-stationary ARFIMA.

For the first stationary and invertible ARFIMA process, the expression given by (5) for the process $x_{t}$ is called a general fractional differenced zero means process, where $d$ is the fractional differencing parameter. This process is both stationary and invertible if the roots of $\Phi(L)$ and $\Theta(L)$ are outside the unit circle, and $d \in(-0.5,0.5)$. The $\operatorname{ARFIMA}(p, d$, $q)$ process exhibits long memory when $d \in(0.0,0.5)$, intermediate memory when $d \in(-0.5,0.0)$, and short memory when $d=0$ (Lopes et al., 2002).

Now, for the second non-stationary ARFIMA process, we define the process (5) with the parameter $d^{*}=d+1$, where $d \in(0.0,0.5)$, yet and the model in (5) becomes:

$$
\Phi(L)(1-L)^{d^{*}} x_{t}=\Theta(L) \epsilon_{t}
$$

The process (6) is non-stationary when $d^{*} \geq 0.5$; however, it is still persistent. For $d^{*} \in(0.5,1.0)$ it is level-reverting in the sense that there is no long-run impact of an innovation on the value of the process (Velasco, 1999). The level reversion property no longer holds when $d^{*} \geq 1$.

\subsection{Data description}

In this study, the yield spreads are measured as the difference between the quoted rates of return of the DJSI AA rated, the DJSI A rated, and the DJSI BBB rated in one hand, and the DJSI AAA rated in the other hand. We calculated three series of yield spreads of Islamic financial certificates (Sukuk) by subtracting the annualised percentage ROI (ROI) of DJSI AA, DJSI A, DJSI BBB from that of instrument DJSI AAA. Market yield is calculated as the difference between $D J S I_{r, t}$ and $D J S I_{r, t-1}$ where subscript $r$ is the rating and $r \in\{A A A, A A, A, B B B\}$.

We analyse the value of 1,305 daily closing prices of the four DJSI $\left(D J S I_{r, t}\right)$ from March 1, 2011 to March 1, 2016. The data are available on (http://www.djindexes.com/sukuk/), and Figure 1 plots the indexes' prices in level. Figure 1 shows that all indexes are following a slight increasing trend during the five-year period. Moreover, the curves of the $D J S I_{A A A}$ and the $D J S I_{B B B}$ are approximately very similar. This applies also to the $D J S I_{A A}$ and the $D J S I_{A}$ which progress following the same path. 
Figure 1 DJSI in level

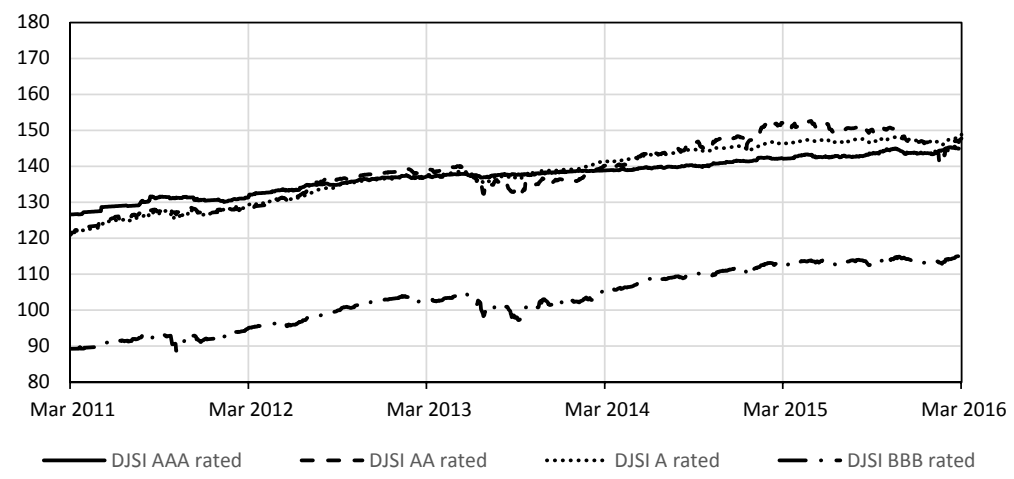

Note: Sample period is March 1, 2011-March 1, 2016 (1,305 days).

Source: http://www.djindexes.com

The calculation of yield spreads uses different formulas, and the most used measure by investors is the absolute yield spread (AYS) which calculates the absolute value of the difference between the (ROI) of two bonds. The other measures of yield spreads are relative yield spreads (RYS) and yield ratio (YT). The graphs (A), (B), and (C) within Figure 2 plot the AYS of the $D J S I_{A A}$ over $D J S I_{A A A}$, the $D J S I_{A}$ over $D J S I_{A A A}$, and the $D J S I_{B B B}$ over $D J S I_{A A A}$ respectively.

Figure 2 AYSs of DJSI

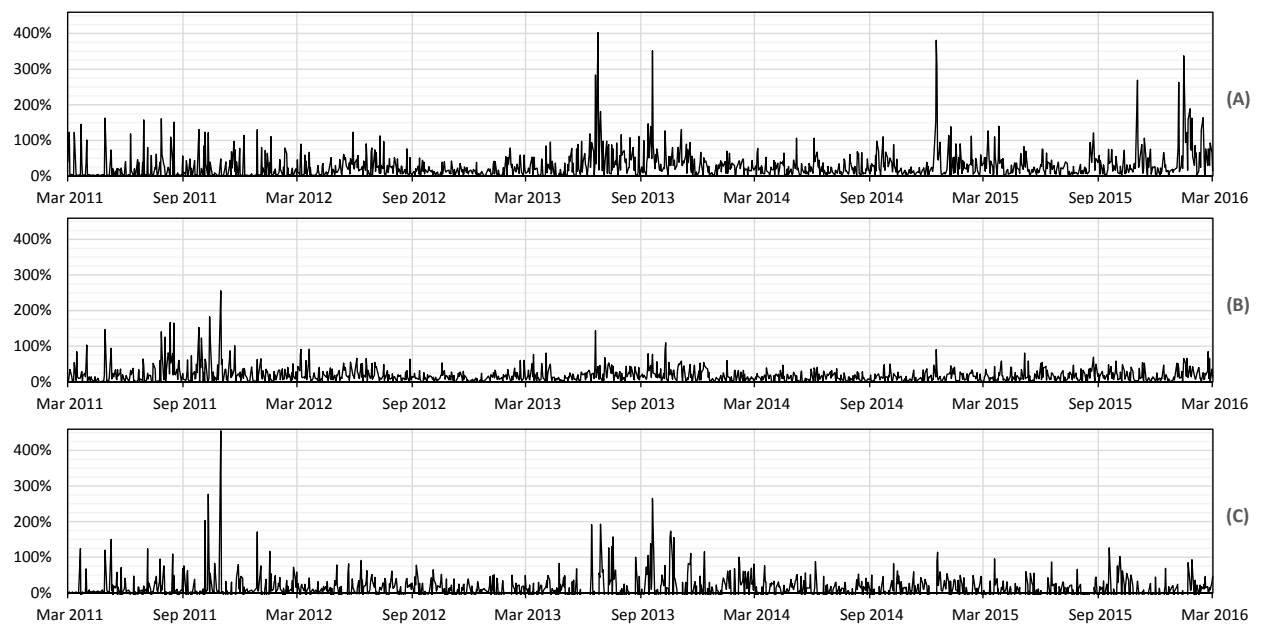

Notes: (a) Absolute yield spreads (AYS) for the $D J S I_{A A}$ over $D J S I_{A A A}$ (b) (AYS) for the $D J S I_{A}$ over $D J S I_{A A A}$ (c) (AYS) for the $D J S I_{B B B}$ over $D J S I_{A A A}$. Sample period is March 1, 2011-March 1, 2016 (1,305 days).

Source: http://www.djindexes.com 
Table 1 contains the values of the augmented Dickey-Fuller and Phillips-Perron statistics for unit root in the AYSs of the four DJSI. Thus, the null hypothesis is that the AYSs follow a non-stationary process, and the alternative hypothesis is that the AYS follow a stationary process. Using the unit root tests advocated by Dickey-Fuller and PhillipsPerron, we reject the null hypothesis for the existence of a unit root for all AYS and we can conclude that these latter are stationary.

Skewness is used to assess the symmetry of the distribution, the kurtosis for peakedness, and the fatness of the tails. If the skewness is positive, the distribution is skewed to the right, and if it is negative, the distribution is skewed to the left. The results for the skewness test, reported in Table 1, show that the distributions of daily AYS are all right-skewed. Also, as evidenced in Table 1, all AYS are leptokurtic, i.e., the excess kurtosis is positive.

Next, the analysis of the distribution of Sukuk' AYS are turned to the Jarque-Bera (JB) statistic introduced by Jarque and Bera (1980). The JB test can be employed to investigate the normality of AYS and it is asymptotically distributed as $\chi^{2}$ under the null hypothesis. If the value of J.B. test statistic is greater than the significance point of $\chi^{2}$, then the null hypothesis of normality is rejected. The results of the JB test presented in Table 1 may conclude that the hypothesis that empirical distributions of the three AYS are drawn from an underlying normal distribution is rejected.

Table 1 Summary statistics, test results of augmented Dickey-Fuller $(\tau)$ and Phillips-Perron $(Z)$

\begin{tabular}{lcccccccc}
\hline & Mean & $\begin{array}{c}\text { Std. } \\
\text { dev. }\end{array}$ & Skewness & Kurtosis & $J B$ & $\tau$ & $Z$ \\
\hline AYS of $D J S I_{A A} / D J S I_{A A A}$ & 0.2811 & 0.3827 & 3.911 & 27.98 & $37,013.35^{*}$ & $-9.85^{\mathrm{a}}$ & $-34.38^{\mathrm{a}}$ \\
AYS of $D J S I_{A} / D J S I_{A A A}$ & 0.1811 & 0.2165 & 3.478 & 24.19 & $26,872.48^{*}$ & $-10.82^{\mathrm{a}}$ & $-35.10^{\mathrm{a}}$ \\
AYS of $D J S I_{B B B} / D J S I_{A A A}$ & 0.2882 & 0.4202 & 5.489 & 53.88 & $146,301.80^{*}$ & $-9.39^{\mathrm{b}}$ & $-37.96^{\mathrm{b}}$ \\
\hline
\end{tabular}

Notes: AYS denotes absolute yield spreads, JB is the Jarque-Bera statistics all significant at $1 \%$ level of significance $\left({ }^{*}\right)$. ${ }^{a}$ Refers to the significance of ADF and PP tests for the trend and the intercept at $1 \%$ level of significance, and ${ }^{\mathrm{b}}$ is for the significance of ADF and PP tests for the constant only at $1 \%$ level of significance.

\section{Results and discussion}

\subsection{Long memory testing}

Since the three series of AYS are stationary, we adopt the MRS for testing long memory in AYS series. The MRS or $\left(R^{\prime} / S_{n}\right)$ are calculated following the method discussed in Subsection 2.1.2. For each sub-period of time horizon $n$, a modified rescaled range $\left(R^{\prime} / S_{n}\right)$ is computed. $\log \left(R^{\prime} / S_{n}\right)$ are plotted against $\log (n)$ in Figure 2. 
Figure 3 Plots of $\log \left(\mathrm{R}^{\prime} / S_{n}\right)$ against $\log (n)$ (see online version for colours)

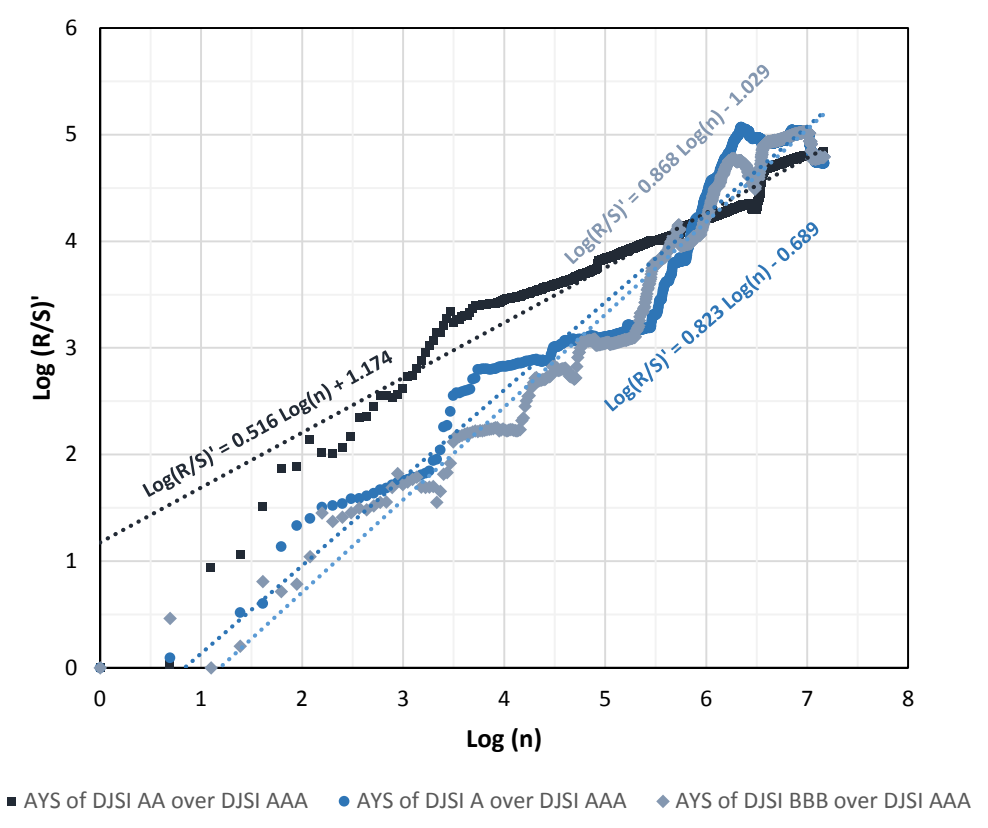

Applying an OLS regression on $\log \left(R^{\prime} / S_{n}\right)$ as a dependent variable and $\log (n)$ as independent variable yielded in:

$$
\begin{aligned}
& \log \left(R^{\prime} / S_{n}\right)=1.174+0.516 \log (n), \text { for AYS of } D J S I_{A A} / D J S I_{A A A} \\
& \log \left(R^{\prime} / S_{n}\right)=-0.689+0.823 \log (n), \text { for AYS of } D J S I_{A} / D J S I_{A A A} \\
& \log \left(R^{\prime} / S_{n}\right)=-1.029+0.868 \log (n), \text { for AYS of } D J S I_{B B B} / D J S I_{A A A}
\end{aligned}
$$

The coefficients of $\log (n)$ are the Hurst exponents $H$, and based on the estimation results, these are all statistically significant at $1 \%$, and they are smaller than one $(H<1)$ meaning that all series exhibit long memory. Following Peters (1994), the fractional differencing parameter $d$ can be obtained by $d=H-0.5$. Therefore, the differencing parameters for the three series are respectively: 0.016 for AYS of $D J S I_{A A} / D J S I_{A A A}, 0.323$ for AYS of $D J S I_{A} / D J S I_{A A A}$, and 0.368 for AYS of $D J S I_{B B B} / D J S I_{A A A}$.

\subsection{Imposing fractional integration on AYSs time series}

The estimation of fractional differencing parameters $d$ for each AYS leads next to obtain the fractionally differenced time series following the formula:

$$
y_{t}=(1-L)^{d} x_{t}
$$

where $L$ is the backshift operator, $y_{t}$ is the fractional differenced time series, and $x_{t}$ is the initial series (Sukuks' AYS). The fractional difference operator is described by: 


$$
\Delta^{d}=(1-L)^{d}=1-d L+\frac{d(d-1)}{2 !} L^{2}-\frac{d(d-1)(d-2)}{3 !} L^{3}+\cdots
$$

Here $\Delta^{d}$ denotes fractional-differencing of order $d$.

\subsection{Specification of ARIMA and ARFIMA models}

Establishing $\operatorname{ARIMA}(p, d, q)$ and $\operatorname{ARFIMA}(p, d, q)$ models requires to determine parameters $p$ and $q$, the orders of the AR model and the MA model respectively. Following the approach proposed by Box and Jenkins (1970), we plot the ACF and partial autocorrelation function (PACF) to decide which AR and/or MA components should be used in the model. Next, we estimate parameters $p$ and $q$ using exact maximum likelihood estimation method. The final step consists in checking for those two conditions on residuals:

1 autocorrelation (Ljung-Box Q test)

2 heteroskedasticity (LM-ARCH test).

Plots of the ACF and PACF of the first-order differenced and the fractionally differenced series of Sukuks' AYS appear in the appendices.

As for the first-order differenced series of Sukuks' AYS, one might notice that for the three series the ACF cut off after the first lag while the PACF die down fairly quickly to become significant after the fifth lag. Following Box and Jenkins, this suggests to select $\mathrm{MA}(1)$ and $\mathrm{M}(2)$ components for all the first-order differenced series.

With respect to the fractionally differenced series of Sukuks' AYS, two cases are presented. As for $D J S I_{A} / D J S I_{A A A}$ and $D J S I_{B B B} / D J S I_{A A A}$, both ACF and PACF die down fairly quickly which supposes to test for mixed $\operatorname{ARMA}(p, q)$ models. We respectively select $\operatorname{ARMA}(4,6)$ and $\operatorname{ARMA}(6,6)$. Alternatively, the ACF of $D J S I_{A A A} / D J S I_{A A A}$ dies down while the PACF cuts off after lag 6. Thus, we select an AR(6) model. It is worth noting that these are just some suspected models, and further candidate models are to be tested with trial and error. The final decision of the best fitting model is based on maximum log likelihood values, Akaike information criterion (AIC) and Schwarz information criterion (SIC).

In general, the reported magnitude of ACF and PACF for all series ranges between 0.004 and 0.362 which are small, indicating that short memory of the data is weak. Also, a number of significant ACF and PACF at later time lags were found. This indicates that there is dependence among distant observations. More importantly, the long lasting autocorrelations evidence indicates according to Taylor (1986), that the processes are nonlinear with time-varying variances.

\subsection{Estimates for specified ARIMA and ARFIMA models}

Table 2 presents the estimates of the selected models for both first-order and fractionally differenced series. Note that Table 2 reports the estimation results for different ARIMA and ARFIMA models from which we selected the best fitting model based on likelihood values, AIC and SIC. As for the diagnostic checking for residuals, two main tests were performed: Ljung and Box (1978) test, and Engle (1982) diagnostic test. 
Table 2 Estimates of ARIMA and ARFIMA models for Sukuks' AYS differenced series

\begin{tabular}{lcccccccc}
\hline & $p$ & $d$ & $q$ & $L L$ & AIC & SIC & Q-stat. & LM-ARCH \\
\hline AYS of $D J S I_{A A} / D J S I_{A A A}$ & 0 & 1 & 1 & -544.87 & 0.844 & 0.852 & $0.063^{(\mathrm{H} 0)}$ & $32.922^{(\mathrm{H} 1)}$ \\
& 0 & 1 & 2 & -540.47 & 0.839 & 0.851 & $0.056^{(\mathrm{H} 0)}$ & $44.982^{(\mathrm{H} 1)}$ \\
& 6 & 0.016 & 0 & -524.04 & 0.819 & 0.847 & $0.062^{(\mathrm{H} 0)}$ & $64.092^{(\mathrm{H} 1)}$ \\
& 7 & 0.016 & 0 & -523.80 & 0.820 & 0.852 & $0.062^{(\mathrm{H} 0)}$ & $65.150^{(\mathrm{H} 1)}$ \\
AYS of $D J S I_{A} / D J S I_{A A A}$ & 0 & 1 & 1 & 171.01 & -0.259 & -0.247 & $0.145^{(\mathrm{H} 0)}$ & $4.200^{(\mathrm{H} 1)}$ \\
& 0 & 1 & 2 & 174.06 & -0.262 & -0.246 & $0.145^{(\mathrm{H} 0)}$ & $6.508^{(\mathrm{H} 1)}$ \\
& 4 & 0.323 & 5 & 193.85 & 0.283 & -0.243 & $0.144^{(\mathrm{H} 0)}$ & $21.122^{(\mathrm{H} 1)}$ \\
& 4 & 0.323 & 6 & 194.00 & -0.282 & -0.238 & $0.142^{(\mathrm{H} 0)}$ & $23.472^{(\mathrm{H} 0)}$ \\
& 6 & 0.323 & 4 & 194.02 & -0.282 & -0.239 & $0.142^{(\mathrm{H} 0)}$ & $23.440^{(\mathrm{H} 0)}$ \\
AYS of $D J S I_{B B B} / D J S I_{A A A}$ & 0 & 1 & 1 & -676.79 & 1.049 & 1.161 & $0.161^{(\mathrm{H} 0)}$ & $0.389^{(\mathrm{H} 0)}$ \\
& 0 & 1 & 2 & -676.58 & 1.051 & 1.067 & $0.162^{(\mathrm{H} 0)}$ & $2.652^{(\mathrm{H} 0)}$ \\
& 0 & 1 & 3 & -675.18 & 1.050 & 1.070 & $0.162^{(\mathrm{H} 0)}$ & $2.934^{(\mathrm{H} 0)}$ \\
& 6 & 0.386 & 6 & -645.37 & 1.017 & 1.073 & $0.117^{(\mathrm{H} 0)}$ & $98.820^{(\mathrm{H} 1)}$ \\
& 7 & 0.386 & 7 & -639.17 & 1.011 & 1.074 & $0.120^{(\mathrm{H} 0)}$ & $106.199^{(\mathrm{H} 1)}$ \\
\hline
\end{tabular}

Notes: AYS denotes absolute yield spreads. $\mathrm{LL}=\log$ likelihood. AIC and SIC are Akaike and Schwarz Information Criteria respectively. Q-stat refers to Box-Ljung' test statistic where the null hypothesis is that residuals are independently distributed (20 lags included). LM-ARCH values are the Observed R-squared statistic of Engle's LM test, the null hypothesis is non-existence of ARCH effect in residuals. Rejection of null hypotheses is considered for $p \leq 0.05$.

The Ljung-Box test was designed to check for autocorrelation within data and it is mostly used when the series represents the residuals from an ARIMA estimation. The test's null hypothesis $\left(\mathrm{H}_{0}\right)$ is that the data are independently distributed, and the alternative $\left(\mathrm{H}_{1}\right)$ is that the data exhibit serial correlation. The Q-test statistic is described by:

$$
Q=n(n+2) \sum_{k=1}^{h} \frac{\hat{\rho}_{k}^{2}}{n-k}
$$

where $n$ is the sample size, $\hat{\rho}_{k}$ is the sample autocorrelation at lag $k$, and $h$ is the number of lags being tested. Under $\mathrm{H}_{0}, Q$ is asymptotically distributed as $\chi_{(h)}^{2}$ with degrees of freedom equal to the number of autocorrelations. If the series represents the residuals from ARIMA estimation, the appropriate degrees of freedom should be adjusted to represent the number of autocorrelations less the number of AR and MA terms previously estimated.

With respect to Engle's (1982) Lagrange multiplier (LM) test for AR conditional heteroskedasticity $(\mathrm{ARCH})$ in the residuals. The test checks for the null hypothesis $\left(\mathrm{H}_{0}\right)$ that there is no ARCH up to order $q$ in the residuals by running the regression of the obtained squared residuals $\hat{\epsilon}_{t}^{2}$ on a constant and $q$ lagged squared residuals:

$$
\hat{\epsilon}_{t}^{2}=\hat{\alpha}_{0}+\sum_{i=1}^{q} \hat{\alpha}_{i} \epsilon_{\hat{t}-i}{ }^{2}
$$


In the absence of ARCH components $\left(\mathrm{H}_{0}\right)$, the parameters $\alpha_{i}=0$ for all $i=1, \cdots, q$. The alternative hypothesis is that, in the presence of ARCH components, at least one of the estimated $\alpha_{i}$ coefficients must be significant. In a sample of $T$ residuals under the null hypothesis of no ARCH errors, the test statistic $T^{\prime} R^{2}$ follows $\chi^{2}$ distribution with $q$ degrees of freedom, where $T^{T}$ is the number of equations in the model which fits the residuals vs. the lags (i.e., $T^{\prime}=T-q$ ). If $T^{\prime} R^{2}$ is greater than the chi-square table value, we reject the null hypothesis and conclude there is an ARCH effect in the ARMA model. If $T^{\prime} R^{2}$ is smaller than the chi-square table value, we do not reject the null hypothesis.

From the estimates above, we select the best fitting models based on maximum positive or minimum negative values of log likelihood, minimum AIC and minimum SIC. The elected models for further predictive power evaluation are: $\operatorname{ARFIMA}(6,0.016,0)$ for AYS of $D J S I_{A A} / D J S I_{A A A}, \operatorname{ARFIMA}(6,0.232,4)$ for AYS of $D J S I_{A} / D J S I_{A A A}$, and $\operatorname{ARFIMA}(7,0.386,7)$ for AYS of $D J S I_{B B B} / D J S I_{A A A}$.

In addition, the examination of the correlogram of ACF and PACF for the residuals indicates that their patterns do not display significant seasonal fluctuations or definite cycles. The Ljung-Box Q statistics of squared residuals demonstrate that there is an overall significant autocorrelation among residuals for all estimated models. This also indicates that the conditional distributions of Sukuk's AYS are time-varying which is a symptom of ARCH effect. With this regard, we consecutively performed the LM-ARCH test to detect the presence of ARCH effects, and the results rejected the null hypothesis of 'no ARCH' in nine cases among 14 suggesting the presence of ARCH effect in AYS of Sukuk.

Based on these results for the Q-statistic of squared residuals and the LM test, it is recommended to use the ARCH specification as a good approximation to the structure of conditional variance of Sukuk's AYS. Moreover, ignoring ARCH effects may result in loss of efficiency.

\subsection{Predictive power comparison}

After determining the best fitting models for AYS of the DJSI, we made a 260-steps ahead forecast (i.e., from March 1, 2015 to March 1, 2016). The competing models are $\operatorname{ARIMA}(0,1,2)$ and $\operatorname{ARFIMA}(7,0.016,0)$ for AYS of $D J S I_{A A} / D J S I_{A A A}$, ARIMA $(0,1,2)$ and $\operatorname{ARFIMA}(6,0.323,4)$ for AYS of $D J S I_{A} / D J S I_{A A A}$, and $\operatorname{ARIMA}(0,1,3)$ and $\operatorname{ARFIMA}(7,0.386,7)$ for AYS of $D J S I_{B B B} / D J S I_{A A A}$. We compared the forecasting power using the root mean squared error (RMSE), the mean absolute error (MAE), Theil inequality coefficient, the bias proportion, the variance proportion and the covariance proportion. These statistics measure the distance of the true from the forecasted values and they are reported in Table 3.

Models with higher predictive power are those for which all measures of forecast accuracy are the smallest. That said, based on the forecasting results reported on Table 3, we can conclude that for all AYS series, the fractionally integrated models perform better for predicting future values than their counterparts (i.e., ARIMA models). 
Table 3 In-sample dynamic forecasting results for estimated ARIMA and ARFIMA models

\begin{tabular}{cccccccccc}
\hline & $p$ & $d$ & $q$ & $R M S E$ & MAE & TIC & $\begin{array}{c}\text { Bias } \\
\text { prop. }\end{array}$ & $\begin{array}{c}\text { Var. } \\
\text { prop. }\end{array}$ & $\begin{array}{c}\text { Cov. } \\
\text { Prop. }\end{array}$ \\
\hline AYS of $D J S I_{A A} / D J S I_{A A A}$ & 0 & 1 & 2 & 0.400 & 0.236 & 0.475 & 0.001 & 0.155 & 0.843 \\
& 7 & 0.016 & 0 & 0.391 & 0.230 & 0.433 & 0.007 & 0.522 & 0.470 \\
${\text { AYS of } D J S I_{A} / D J S I_{A A A}}$ & 0 & 1 & 2 & 0.164 & 0.124 & 0.444 & 0.001 & 0.238 & 0.759 \\
& 6 & 0.323 & 4 & 0.162 & 0.124 & 0.391 & 0.000 & 0.614 & 0.385 \\
${\text { AYS of } D J S I_{B B B} / D J S I_{A A A}}$ & 0 & 1 & 3 & 0.234 & 0.177 & 0.437 & 0.000 & 0.171 & 0.828 \\
& 7 & 0.386 & 7 & 0.236 & 0.180 & 0.378 & 0.000 & 0.532 & 0.467 \\
\hline
\end{tabular}

Notes: AYS denotes AYSs; root mean squared error (RMSE); mean absolute error

(MAE); Theil inequality coefficient (TIC). These are results of

260-steps ahead forecast (from March 1, 2015 to March 1, 2016).

Furthermore, the estimated forecast values from ARFIMA models are more realistic and closely reflect the current variation of Sukuk's yield spreads. These results are in agreement with Shittu and Yaya (2009), Wang (2006), and Boutahar et al. (2008). Thus, when series exhibits long memory property, the forecast values based on ARIMA model may not be reliable, and the fractionally integrated model may perform better for fitting the data and forecasting.

In order to improve the forecasting power of ARFIMA models for Sukuk's AYS, we believe that further consideration should be given to seasonal effect identified on the data (significant $\mathrm{ACF}$ and PACF at later time lags), and the present $\mathrm{ARCH}$ effect by using other models (e.g., Seasonal ARFIMA, ARFIMA-GARCH, Fractional Integrated GARCH...)

\section{Conclusions and future work}

In this paper, we used the MRS to test for the long memory property in three series of AYS of the DJSI, namely, AYS of the DJSI AA rated over DJSI AAA rated, AYS of the DJSI A rated over DJSI AAA rated, and the DJSI BBB rated over DJSI AAA rated. The data sample is from March 1, 2011 to March 1, 2016.

The Hurst exponents ' $H$ ' obtained for the three series via MRS are respectively, $H=0.516, H=0.823$, and $H=0.886$. These three parameters are all significant and smaller than one $(H<1)$ suggesting the presence of long memory in Sukuk's yield spreads series. A reasonable explanation of long memory in Sukuk's yield spreads is the persistence of risk premiums. Rating agencies do not frequently adjust Sukuk's ratings to reflect the changes in issuers' financial conditions. Such result testifies the lack of willingness or capability of the rating agencies to make timely rating adjustments.

Using the calculated Hurst exponents, we next deducted the fractional differencing parameters ' $d$ ' of the AR fractionally integrated moving average models $\operatorname{ARFIMA}(p, d$, $q)$ for the three series. By comparing the latter to the first-order differenced ARIMA models, we found that ARFIMA models fit better the data and have more forecasting power. In fine, we selected three models for Sukuk's AYS and these are: $\operatorname{ARFIMA}(7,0.016,0)$ for AYS of $D J S I_{A A} / D J S I_{A A A}$; $\operatorname{ARFIMA}(6,0.323,4)$ for AYS of $D J S I_{A} / D J S I_{A A A}$; and $\operatorname{ARFIMA}(7,0.386,7)$ for AYS of $D J S I_{B B B} / D J S I_{A A A}$. These findings 
are in agreement with Wang (2006), Boutahar et al. (2008) and Shittu and Yaya (2009), and support the use of the fractionally integrated models for yield spread analysis and default risk anticipation on Islamic capital market.

In addition, our investigation pointed out the presence of seasonality and time varying conditional variance (ARCH effect) in Sukuk's yield spreads. Such facts motivate us to use the ARCH specification as a good approximation to the structure of conditional variance of Sukuk's AYS. Our forthcoming work should give further consideration to seasonality in Sukuk's AYS using seasonal ARFIMA model with volatility SARFIMA-GARCH (see, for example, Bordignon et al., 2005; Kallberg, 2008; Reisen et al., 2014; Ndongo et al., 2015).

\section{References}

Alvarez-Ramirez, J., Alvarez, J., Rodriguez, E. and Fernandez-Anaya, G. (2008) 'Time varying Hurst exponent for us stock markets', Physica A: Statistical Mechanics and Its Applications, Vol. 387, No. 24, pp.6159-6169.

Andersson, M.K. (2000) 'Do long-memory models have long memory?', International Journal of Forecasting, Vol. 16, No. 1, pp.121-124.

Baillie, R.T. (1996) 'Long memory processes and fractional integration in econometrics', Journal of Econometrics, Vol. 73, No. 1, pp.5-59.

Baillie, R.T. and Chung, S-K. (2002) 'Modeling and forecasting from trend-stationary long memory models with applications to climatology', International Journal of Forecasting, Vol. 18, No. 2, pp.215-226.

Bank of Sweden (2003) Time-Series Econometrics: Cointegration and Autoregressive Conditional Heteroskedasticity, The Royal Swedish Academy of Sciences, Advanced information on the Bank of Sweden Prize in Economic Sciences in Memory of Alfred Nobel, Vol. 8.

Beran, J., Feng, Y., Ghosh, S. and Sibbertsen, P. (2002) 'On robust local polynomial estimation with long-memory errors', International Journal of Forecasting, Vol. 18, No. 2, pp.227-241.

Bhansali, R.J. and Kokoszka, P.S. (2002) 'Computation of the forecast coefficients for multistep prediction of long-range dependent time series', International Journal of Forecasting, Vol. 18, No. 2, pp.181-206.

Bhardwaj, G. and Swanson, N.R. (2006) 'An empirical investigation of the usefulness of ARFIMA models for predicting macroeconomic and financial time series', Journal of Econometrics, Vol. 131, No. 1, pp.539-578.

Bordignon, S., Caporin, M. and Lisi, F. (2005) SFIGARCH: A Seasonal Long Memory GARCH Model.

Bos, C.S., Franses, P.H. and Ooms, M. (2002) 'Inflation, forecast intervals and long memory regression models', International Journal of Forecasting, Vol. 18, No. 2, pp.243-264.

Boutahar, M., Dufrénot, G. and Péguin-Feissolle, A. (2008) 'A simple fractionally integrated model with a time-varying long memory parameter dt', Computational Economics, Vol. 31, No. 3, pp.225-241.

Box, G.E.P. and Jenkins, G.M. (1970) 'Time series', Forecasting and Control, Hoiden-Day, San Francisco.

Breitung, J. and Hassler, U. (2002) 'Inference on the cointegration rank in fractionally integrated processes', Journal of Econometrics, Vol. 110, No. 2, pp.167-185.

Carbone, A., Castelli, G. and Stanley, H.E. (2004) 'Time-dependent Hurst exponent in financial time series', Physica A: Statistical Mechanics and Its Applications, Vol. 344, No. 1, pp.267-271. 
Cheung, Y-W. and Diebold, F.X. (1994) 'On maximum likelihood estimation of the differencing parameter of fractionally-integrated noise with unknown mean', Journal of Econometrics, Vol. 62, No. 2, pp.301-316.

Choi, K. and Zivot, E. (2007) 'Long memory and structural changes in the forward discount: an empirical investigation', Journal of International Money and Finance, Vol. 26, No. 3, pp.342-363.

Czarnecki, Ł., Grech, D. and Pamuła, G. (2008) 'Comparison study of global and local approaches describing critical phenomena on the polish stock exchange market', Physica A: Statistical Mechanics and Its Applications, Vol. 387, No. 27, pp.6801-6811.

Di Matteo, T. (2007) 'Multi-scaling in finance', Quantitative Finance, Vol. 7, No. 1, pp.21-36.

Di Matteo, T., Aste, T. and Dacorogna, M.M. (2005) 'Long-term memories of developed and emerging markets: using the scaling analysis to characterize their stage of development', Journal of Banking and Finance, Vol. 29, No. 4, pp.827-851.

Diebold, F.X. and Inoue, A. (2001) 'Long memory and regime switching', Journal of Econometrics, Vol. 105, No. 1, pp.131-159.

Diebold, F.X. and Rudebusch, G.D. (1989) 'Long memory and persistence in aggregate output', Journal of Monetary Economics, Vol. 24, No. 2, pp.189-209.

Diebold, F.X. and Rudebusch, G.D. (1991a) 'On the power of dickey-fuller tests against fractional alternatives', Economics Letters, February, Vol. 35, No. 2, pp.155-160.

Diebold, F.X. and Rudebusch, G.D. (1991b) 'Is consumption too smooth? Long memory and the Deaton paradox', The Review of Economics and Statistics, Vol. 73, No. 1, pp.1-9.

Ding, Z., Granger, C. and Engle, R. (1993) '1A Long memory property of stock returns and a new model1', Journal of Empirical Finance, Vol. 1, No. 1, pp.83-106.

Dittmann, I. and Granger, C.W.J. (2002) 'Properties of nonlinear transformations of fractionally integrated processes', Journal of Econometrics, Vol. 110, No. 2, pp.113-133.

Engle, R.F. (1982) 'A general approach to Lagrange multiplier model diagnostics', Journal of Econometrics, Vol. 20, No. 1, pp.83-104.

Engle, R.F. and Smith, A.D. (1999) 'Stochastic permanent breaks', Review of Economics and Statistics, Vol. 81, No. 4, pp.553-574.

Franses, P.H. and Ooms, M. (1997) 'A periodic long-memory model for quarterly UK inflation', International Journal of Forecasting, Vol. 13, No. 1, pp.117-126.

Granger, C.W.J. (1980) 'Long memory relationships and the aggregation of dynamic models', Journal of Econometrics, Vol. 14, No. 2, pp.227-238.

Granger, C.W.J. and Joyeux, R. (1980) 'An introduction to long-memory time series models and fractional differencing', Journal of Time Series Analysis, Vol. 1, No. 1, pp.15-29.

Grech, D. and Mazur, Z. (2004) 'Can one make any crash prediction in finance using the local Hurst exponent idea?', Physica A: Statistical Mechanics and Its Applications, Vol. 336, No. 1, pp.133-145.

Hassler, U. and Wolters, J. (1995) 'Long memory in inflation rates: international evidence', Journal of Business and Economic Statistics, Vol. 13, No. 1, pp.37-45.

Hosking, J.R.M. (1981) 'Fractional differencing', Biometrika, Vol. 68, No. 1, pp.165-176.

Hurst, H.E. (1951) 'Long-term storage capacity of reservoirs', Trans. Amer. Soc. Civil Eng., Vol. 116, No. 776, pp.770-808.

Hyung, N., Franses, P.H. and Penm, J. (2006) 'Structural breaks and long memory in us inflation rates: do they matter for forecasting?', Research in International Business and Finance, Vol. 20, No. 1, pp.95-110.

Jarque, C.M. and Bera, A.K. (1980) 'Efficient tests for normality, homoscedasticity and serial independence of regression residuals', Economics Letters, Vol. 6, No. 3, pp.255-259.

Kallberg, D. (2008) Modeling Electricity Prices with Seasonal Long Memory Time Series, August. 
Ljung, G.M. and Box, G.E.P. (1978) 'On a measure of lack of fit in time series models', Biometrika, Vol. 65, No. 2, pp.297-303.

Lo, A.W. (1989) Long-Term Memory in Stock Market Prices, Technical Report, National Bureau of Economic Research.

Lo, A.W. (1991) 'Long-term memory in stock market prices', Econometrica, Vol. 59, No. 5, pp.1279-1313.

Lopes, S.R.C., Olbermann, B.P. and Reisen, V.A. (2002) 'Non-stationary Gaussian ARFIMA processes: estimation and application', Brazilian Review of Econometrics, Vol. 22, No. 1, pp.103-126.

Man, K.S. (2003) 'Long memory time series and short term forecasts', International Journal of Forecasting, Vol. 19, No. 3, pp.477-491.

Mandelbrot, B.B. (1971) 'Analysis of long-run dependence in economics: the R/S technique', Econometrica, Vol. 39, pp.68-69.

Mandelbrot, B.B. and Van Ness, J.W. (1968) 'Fractional Brownian motions, fractional noises and applications', SIAM Review, Vol. 10, No. 4, pp.422-437.

Matos, J.A.O., Gama, S.M.A., Ruskin, H.J., Al Sharkasi, A. and Crane, M. (2008) 'Time and scale Hurst exponent analysis for financial markets', Physica A: Statistical Mechanics and Its Applications, Vol. 387, No. 15, pp.3910-3915.

Ndongo, M., Diongue, A.K. and Dossou-Gbété, S. (2015) Seasonal Fractional ARIMA Model with BL-GARCH Type Innovations, Unpublished, February.

Öller, L-E. (1985) 'How far can changes in general business activity be forecasted?', International Journal of Forecasting, Vol. 1, No. 2, pp.135-141.

Peng, C-K., Buldyrev, S.V., Havlin, S., Simons, M., Stanley, H.E. and Goldberger, A.L. (1994) 'Mosaic organization of DNA nucleotides', Physical Review E, Vol. 49, No. 2, pp.16-85.

Peters, E.E. (1994) Fractal Market Analysis: Applying Chaos Theory to Investment and Economics, Vol. 24, John Wiley \& Sons.

Ramjee, R., Crato, N. and Ray, B.K. (2002) 'A note on moving average forecasts of long memory processes with an application to quality control', International Journal of Forecasting, Vol. 18, No. 2, pp.291-297.

Ravishanker, N. and Ray, B.K. (2002) 'Bayesian prediction for vector ARFIMA processes', International Journal of Forecasting, Vol. 18, No. 2, pp.207-214.

Ray, B.K. (1993a) 'Long-range forecasting of IBM product revenues using a seasonal fractionally differenced ARMA model', International Journal of Forecasting, Vol. 9, No. 2, pp.255-269.

Ray, B.K. (1993b) 'Modeling long-memory processes for optimal long-range prediction', Journal of Time Series Analysis, Vol. 14, No. 5, pp.511-525.

Reisen, V.A., Sarnaglia, A.J.Q., Reis, N.C., Lévy-Leduc, C. and Santos, J.M. (2014) 'Modeling and forecasting daily average pm 10 concentrations by a seasonal long-memory model with volatility’, Environmental Modelling and Software, January, Vol. 51, No. 1, pp.286-295.

Robinson, P.M. (1995a) 'Gaussian semiparametric estimation of long range dependence', The Annals of Statistics, Vol. 23, No. 5, pp.1630-1661.

Robinson, P.M. (1995b) 'Log-periodogram regression of time series with long range dependence', The Annals of Statistics, Vol. 23, No. 3, pp.1048-1072.

Shittu, O.I. and Yaya, O.S. (2009) 'Measuring forecast performance of ARMA and ARFIMA models: an application to US dollar/UK pound foreign exchange rate', European Journal of Scientific Research, Vol. 32, No. 2, pp.167-176.

Simkovic, M. and Kaminetzky, B.S. (2011) 'Leveraged buyout bankruptcies, the problem of hindsight bias, and the credit default swap solution', Colum. Bus. L. Rev., Vol. 2001, No. 1, p. 118 .

Smith, J. and Yadav, S. (1994) 'Forecasting costs incurred from unit differencing fractionally integrated processes', International Journal of Forecasting, Vol. 10, No. 4, pp.507-514. 
Souza, L.R. and Smith, J. (2002) 'Bias in the memory parameter for different sampling rates', International Journal of Forecasting, Vol. 18, No. 2, pp.299-313.

Souza, L.R. and Smith, J. (2004) 'Effects of temporal aggregation on estimates and forecasts of fractionally integrated processes: a Monte-Carlo study', International Journal of Forecasting, Vol. 20, No. 3, pp.487-502.

Sowell, F. (1992a) 'Maximum likelihood estimation of stationary univariate fractionally integrated time series models', Journal of Econometrics, Vol. 53, No. 1, pp.165-188.

Sowell, F. (1992b) 'Modeling long-run behavior with the fractional ARIMA model', Journal of Monetary Economics, Vol. 29, No. 2, pp.277-302.

Taylor, S. (1986) Modelling Financial Time Series, John Wiley \& Sons, Great Britain.

Van Dijk, D., Franses, P.H. and Paap, R. (2002) 'A nonlinear long memory model, with an application to us unemployment', Journal of Econometrics, Vol. 110, No. 2, pp.135-165.

Velasco, C. (1999) 'Non-stationary log-periodogram regression', Journal of Econometrics, Vol. 91, No. 2, pp.325-371.

Wang, W. (2006) Stochasticity, Nonlinearity and Forecasting of Streamflow Processes, A doctoral thesis, IOS Press, Delft Technical University, ISBN: 1-58603-621-1 [online] http://repository.tudelft.nl/.

Weron, R. (2002) 'Estimating long-range dependence: finite sample properties and confidence intervals', Physica A: Statistical Mechanics and Its Applications, Vol. 312, No. 1, pp.285-299.

\section{Notes}

1 AAOIFI Standard 17.

2 See DJSI fact sheet, retrieved March 3, 2016 available on http://www.djindexes.com.

3 Bhardwaj and Swanson (2006) referenced many other empirical and theoretical studies for the fractional integration models.

4 See Bank of Sweden (2003). 


\section{Appendix}

Figure A1 ACF and PACF correlogram for AYS $D J S I_{A A} / D J S I_{A A A}$, (a) first-order differenced (b) fractionally differenced (see online version for colours)

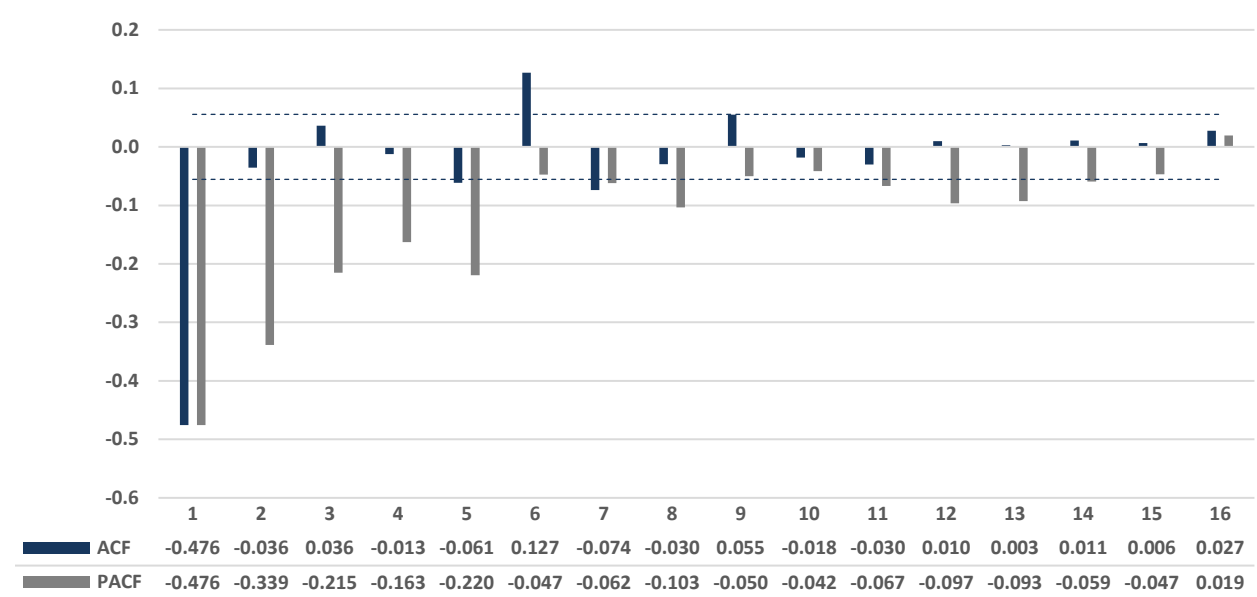

(a)

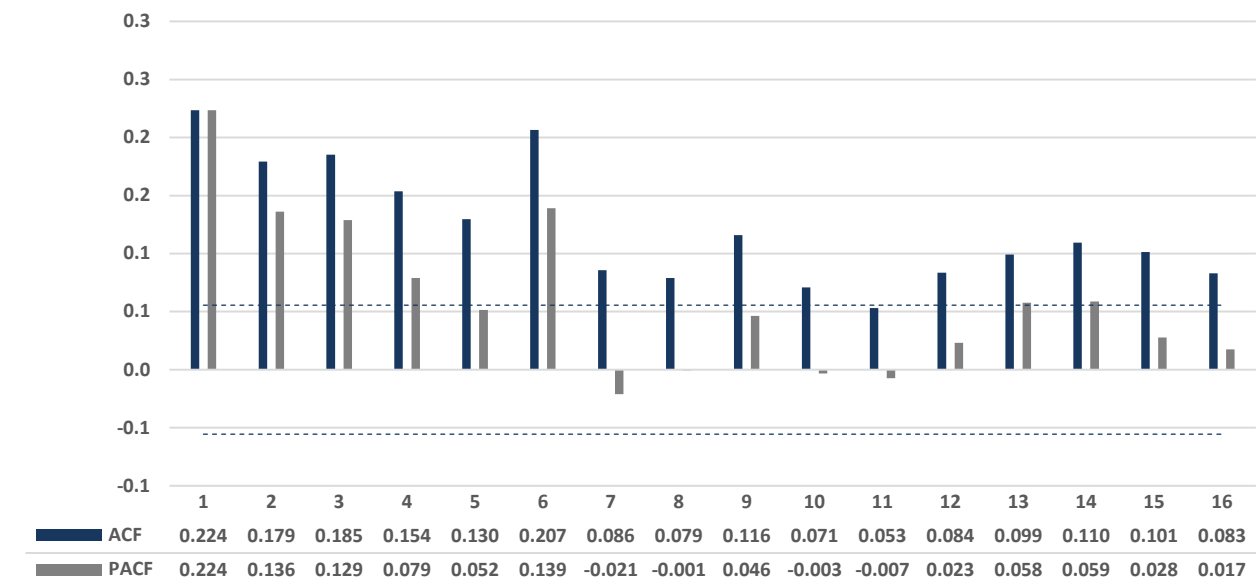

(b) 
Figure A2 ACF and PACF correlogram for AYS $D J S I_{A} / D J S I_{A A A}$, (a) first-order differenced (b) fractionally differenced (see online version for colours)

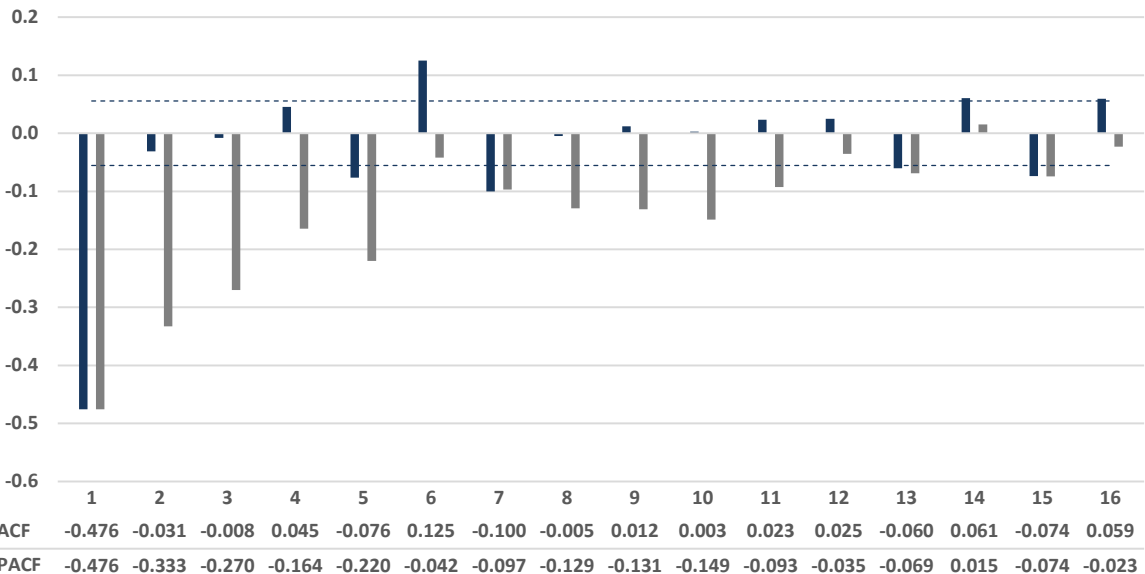

(a)

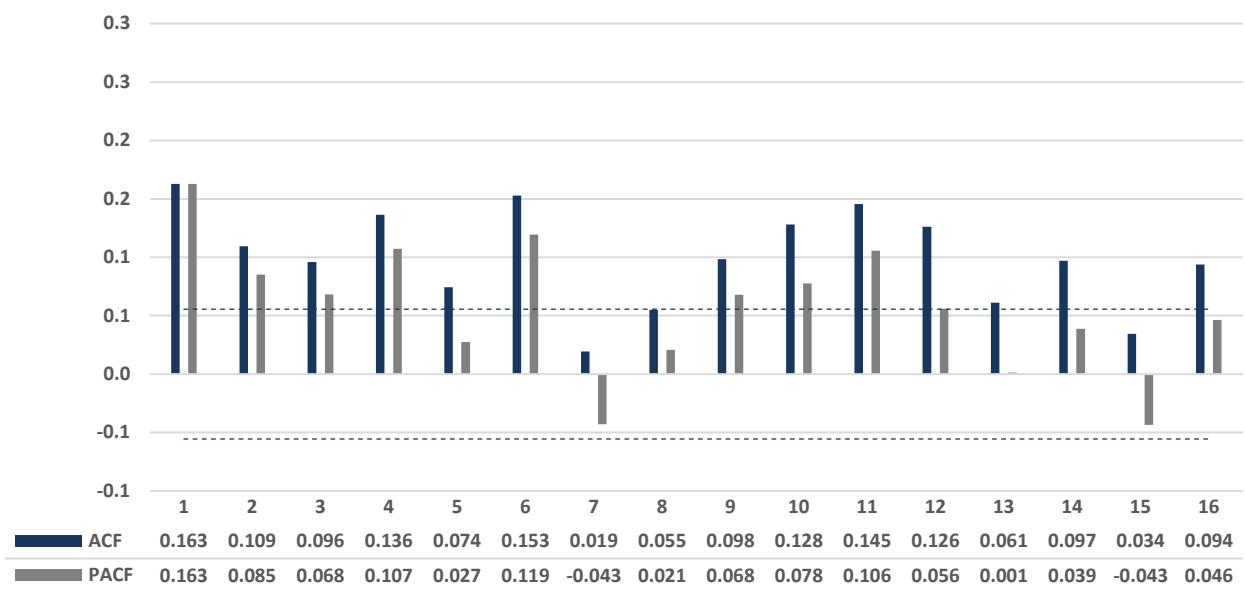

(b) 
Figure A3 ACF and PACF correlogram for AYS $D J S I_{A} / D J S I_{A A A}$, (a) first-order differenced (b) fractionally differenced (see online version for colours)

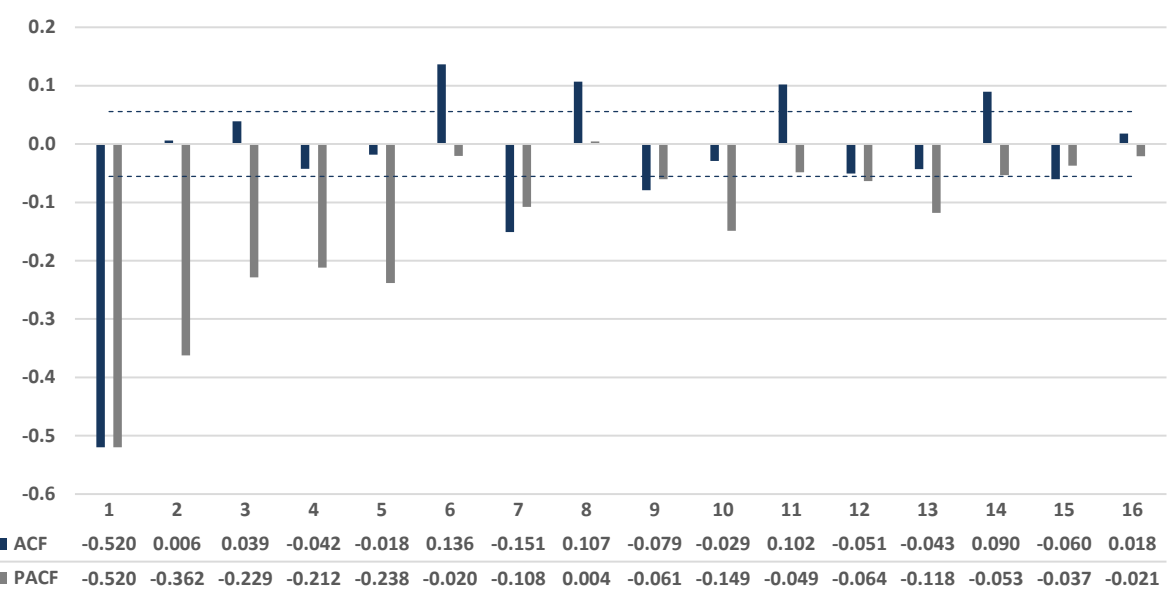

(a)

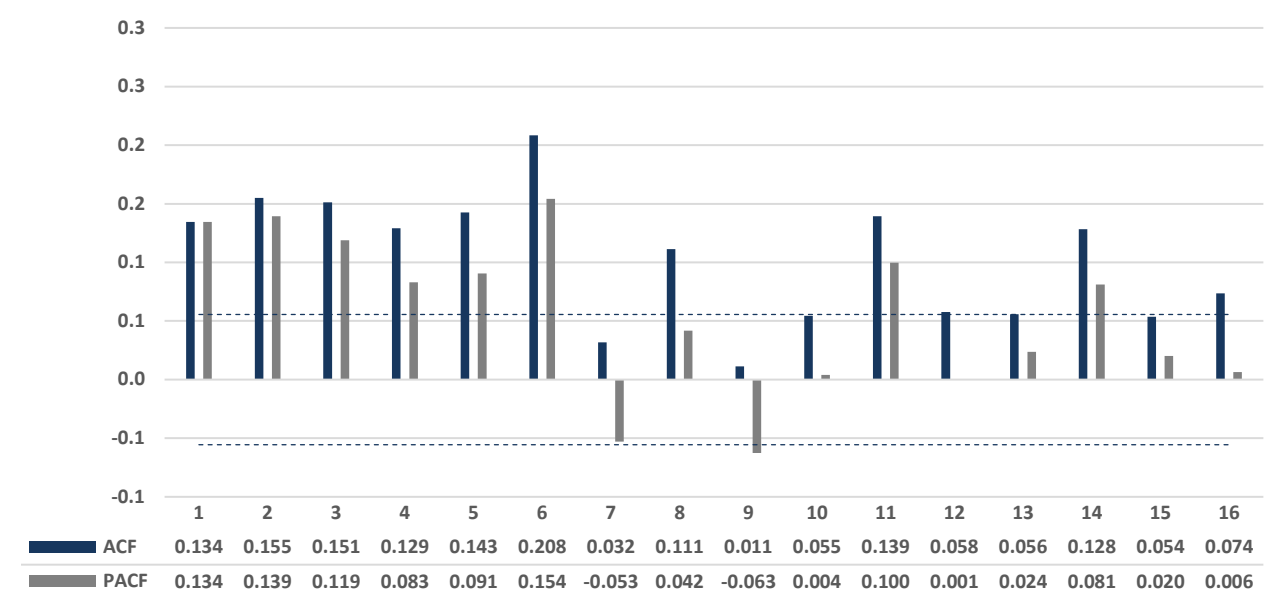

(b) 